tioned, but the movement is distinctly outward and slightly upward. The movements of each segment differ in time, conforming to the movement of the segment of the heart beneath.

Occasionally a thymus will be found which gives four lateral borders by fluoroscope and plate, two on each side. The pair internal lie close to the borders of the sternum. The second pair is seen at a considerable distance externally. It has been supposed that the two inner lines represent the lateral borders of a median lobe, and that the lines external represent the external lateral borders of two lateral lobes.

I have attempted to conform Boggs' $\operatorname{sign}^{2}$ to this method of examination, but have failed to confirm it. Boggs asserted that the percussion border of the hyperplastic thymus moves upward and downward with extreme extension and flexion of the head. This sign is sometimes obscured by evidences of former tuberculous processes, and especially pleural arlhesions. A study of the movements previously detailed considered in connection with evidences of such conditions will lead to a correct interpretation.

Possible sources of error should be kept in mind as follows:

1. A hyperplastic third or inferior lobe of the thyroid sometimes occupies a position in the critical space of Grawitz. I have not seen such a case, but on theoretical grounds believe that the shadow would be more dense than a thymus persistans. It should not be forgotten that at least 90 per cent. of enlarged thyroids are accompanied by hyperplastic thymus glands. The shadow of a thyroid lobe in this position should rise and fall in the act of swallowing.

2. The absence of a characteristic thymus shadow loes not exclude its presence. Hyperplastic thymus tissue sometimes extends from the base of the tongue to the apex of the heart. It may hide behind the sternum, so far as the fluoroscope is concerned, enlargement having taken place in an anteroposterior direction (Halsted ${ }^{3}$ ).

3. A thymus shadow may be cast by the fat which replaces the lymphoid tissue during the normal involution of that gland. It appears doubtful if this could cause confusion to the extent of a positive error in diagnosis. It should not be forgotten that hyperthymization (Svehla) may possibly arise from a very small and insignificant persisting remnant, the presence of which could not be directly diagnosticated by any method now available.

4. The differential diagnosis between thymus hyperplasia and mediastinal tumors presents no unusual difficulties. 'The appearance of pressure on the bronchial tree is conclusive. The obstruction which blood presents to the passage of the Roentgen ray gives a characteristic appearance to aortic aneurysms.

2. Boggs: Tr. Assn. Am. Phys., 1911, xxvi, 353.

3. Halsted: Harvey Society Lectures, 1913-1914, Series 9, p. 241.

The Mental Hospital of the Future.-In the hospital for the insane of the future there will be no locks and bars or secured doors and windows. For these means of restraint there will have been substituted plain, human, socialized intelligence. Wards will be on the ground floor. Physicians and nurses will be, not only technically trained in a distinct and recognized profession, but they will have received in addition a knowledge of practical psychology and sociology. The social problems involved in the insane and in their care and treatment, will be given as careful consideration as tha medical problems.-Institution Quarterly (III.)

\section{STUDY OF LATER CASES OF SCARLET FEVER OCCURRING IN BROOKLYN}

- B. FRANK KNAUSE, M.D.

Borough Chief, Bureau of Preventable Diseases, Department of Health, City of New York

NEW YORK

In an article by G. B. Young, ${ }^{1}$ Commissioner of Health of Chicago, justification is apparently furnished for the classified quarantine of cases of scarlet fever and diphtheria as enforced in that city at the present time. Statistics given by Young are reproduced in Tables 1 and 2 .

TABLE 1.-SCARLET FEVER IN CHICAGO, MARCH 15, 1914, To NOV. 1, 1914 (FROM YOUNG)

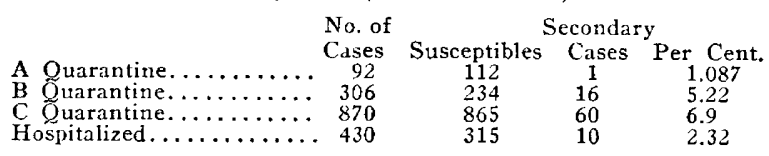

TABLE 2.-SECONDARY CASES OF SCARLET FEVER IN NEW YORK CITY (FROM YOUNG)

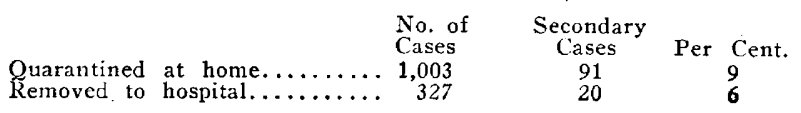

The statistics quoted under Table 2 . showing secondary cases in New York City, were so out of proportion to those of Chicago, as shown in Table 1, that a study was undertaken of 1,610 cases of scarlet fever occurring in Brooklyn at about the same period, namely, March to December, 1914.

The term "later cases" has been used in preference to "return cases," which is evidently a misnomer as applied to cases of scarlet fever. The term "later cases" as used in this study applies only to those later cases whose onset is subsequent to the first report received by the department of health of a case of scarlet fever. If four cases in a family were reported by the attending physician at the same time, even though the onset of each varied, they were considered as four primary cases, provided no previous case had been reported in this family. This procedure is justifiable inasmuch as this study is one to determine the value of quarantine in relation to later cases, and the responsibility of the department of health begins from the date of receipt of the first report of a case.

The health department of the city of New York maintains only two classes of quarantine, namely, "observation" and "supervision" cases.

A. Observation Cases.-Cases which require infrequent visits to maintain proper isolation. This may mean a number of things. The house may be a private dwelling, two-family house or tenement, but the intelligence of the people and their desire to maintain isolation must be evident. A trained nurse may or may not be in attendance. The number, location of rooms, size of family and the presence of susceptibles are considered in determining if the case should be considered as an observation case.

B. Superzision Cases.-Those in which it is evident that proper isolation will not be maintained without careful watching on the part of the field force. In these cases, when violations of proper isolation

1. Young, G. B.: Occurrence of Return Cases of Scarlet Fever

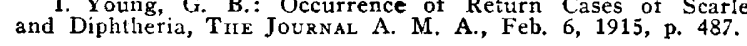


are noted, the attending physician is first notified and a patrolman sent to warn the family that removal to the hospital will be forcel if a second violation occurs. On the second report of failure to isolate properly, removal to the hospital is forced.

The determination as to class of case is left entirely to the judgment of the field worker, the district nurse. At the time of her first visit in making out her history card, Form $20-\mathrm{J}$, she notes on the reverse side "observation" or "supervision" case and the date on which the patient is to be revisited. The supervision case must be visited every two or three days, while an observation case may be completed in two visitsthe primary visit when history is taken and the final visit when case is terminated. As the quantity of work is very large at times, the number of field workers too meager; and as nurses are human, the temptation to consider cases as "observation" instead of "supervision" occurs, and the lack of proportion between the two classes of cases, as shown in the study, is evidence that it has been easy to yield to temptation.

Quarantine, as understood by the district nurse, applies to the patient alone; others, with the exception of attendants, are kept from coming in contact with the patient who is considered the source of infection.

TABLE 3.-CASES S'UDIED

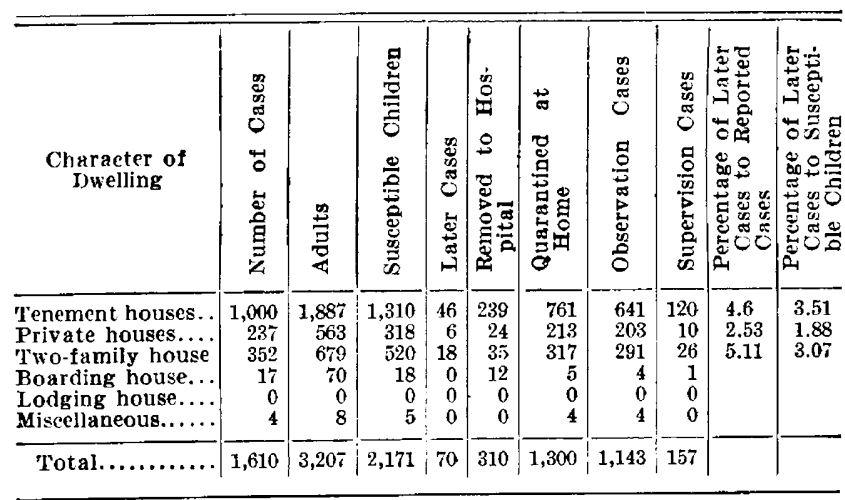

A hanging card is left with the family giving instructions under the head of "Precautions" as follows:

During the illness, all unnecessary furniture, such as curtains, carpets and pictures, should be removed from the sickroom.

Dogs, cats and other pets should be kept out of the sickroom, as they often carry the disease to others.

Discharges from the mouth, throat and nose should be received on cloths and immediately burned or boiled.

Bed linen, towels, napkins, etc., should be disinfected by soaking in a solution of 2.5 per cent. carbolic acid. This should be done before goods are removed from sickroom. These goods should then be boiled in soap suds for one-half hour. The patient's nigitgowns, sheets, etc., should be soaked in the solution of carbolic acid and washed in hot soap suds.

Dishes and utensils used by the patient should be kept in the sickroom until recovery, unless scalded with boiling water before removal. The nurse or attendant, while in the sickroom, should wear a special gown or outer garment, completely covering her clothing. On leaving the room, she should soak her hands in a disinfecting solution and then wash them in hot soap suds. Urine and stools, immediateiy after being received in a vessel, should be covered with an equal quantity of a solution of one tablespoonful of chlorid of lime in one quart of water, and allowed to stand fifteen minutes before emptying.
Upon recovery, the patient should be bathed and hair washed in warm soap suds, then dressed in clean clothes which have not been in the sickroom.

The members of the family and the attendant are not prevented from using public halls, and entering public conveyances or places of assembly. If the patient is properly quarantined, children in private houses may attend public school on special school per-

TABLE 4.-PERCENTAGE OF LATER CASES

\begin{tabular}{|c|c|c|c|}
\hline & $\begin{array}{c}\text { Number of } \\
\text { Cases }\end{array}$ & $\begin{array}{l}\text { Later } \\
\text { Cases }\end{array}$ & Percentage \\
\hline $\begin{array}{l}\text { Observation } \ldots \ldots \ldots \ldots \ldots \\
\text { Supervision } \ldots \ldots \ldots \ldots \\
\text { Entered Hospital } \ldots \ldots \ldots\end{array}$ & $\begin{array}{r}1,143 \\
157 \\
310\end{array}$ & $\begin{array}{l}46 \\
13 \\
11\end{array}$ & $\begin{array}{l}4.02 \\
8.28 \\
3.54\end{array}$ \\
\hline
\end{tabular}

TABLE 5,-LATER CASES

\begin{tabular}{|c|c|c|c|c|c|c|c|c|c|c|}
\hline 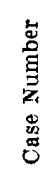 & 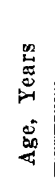 & 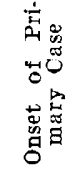 & 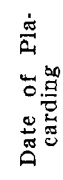 & 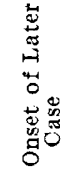 & 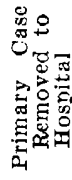 & $\begin{array}{l}\stackrel{9}{0} \\
\stackrel{0}{0} \\
0 \\
0 \\
0 \\
0 \\
0\end{array}$ & $\begin{array}{l}\frac{D}{0} \\
\frac{0}{2} \\
0 \\
0 \\
0 \\
0\end{array}$ & 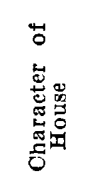 & 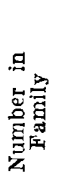 & 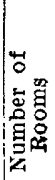 \\
\hline 1 & 2 & $6 / 19$ & $6 / 22$ & 7/ 9 & … & Yes & & Ten, & 5 & 4 \\
\hline 2 & 7 & $8 / 13$ & $8 / 10$ & $8 / 26$ & $\cdots$ & ... & Yes & 'Ten. & 7 & $\begin{array}{l}4 \\
4\end{array}$ \\
\hline 3 & 4 & $7 / 16$ & $7 / 18$ & $8 / 10$ & ... & & Yes & $2 \mathrm{Fam}$. & 8 & \\
\hline 4 & 7 & $6 / 25$ & $6 / 27$ & $6 / 30$ & & Yes & .... & 2 Fam. & 6 & 7 \\
\hline 5 & 9 & $8 / 23$ & $8 / 25$ & $8 / 31$ & $8 / 25$ & & $\ldots$ & $2 \mathrm{Fam}$. & 6 & J \\
\hline 6 & 14 & $8 / 13$ & $8 / 18$ & $8 / 16$ & $\ldots$ & Yes & $\ldots$ & $2 \mathrm{Fam}$. & 7 & 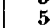 \\
\hline 7 & 7 & $6 / 22$ & $8 / 18$ & $8 / 13$ & $\ldots$ & Yes & .... & 2 Fam. & 7 & 5 \\
\hline 8 & 3 & $8 / 13$ & $8 / 18$ & $9 / 2$ & $\ldots$ & Yes & .... & 2 Fam. & 7 & ] \\
\hline 9 & 4 & $7 / 26$ & $7 / 30$ & $7 / 31$ & $\ldots$ & Yes & $\ldots$ & 'Ten. & 6 & $\mathbf{4}$ \\
\hline 10 & 16 & $6 / 14$ & $6 / 20$ & $7 / 3$ & $\ldots$ & Yes & $\ldots$ & 2 Fam. & 7 & 6 \\
\hline 11 & 5 & $6 / 24$ & 7) 7 & $7 / 10$ & $\ldots$ & Xes & .... & Ten. & 6 & 8 \\
\hline 12 & 3 & $6 / 24$ & 7) 7 & $7 / 10$ & $\ldots$ & Yes & $\ldots$. & Ten. & 6 & 8 \\
\hline 13 & $20^{*}$ & $6 / 24$ & 7) 7 & $7 / 10$ & $\ldots$ & Yes & $\ldots$. & Ten. & 6 & 8 \\
\hline 14 & 7 & $4 / 20$ & $4 / 25$ & $4 / 27$ & $\ldots$ & Yes & .... & P. H. & 10 & 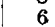 \\
\hline 15 & 4 & $4 / 20$ & $4 / 25$ & $4 / 27$ & $\ldots$ & Yes & .... & P. $\mathrm{H}$, & 10 & 6 \\
\hline 16 & 2 & $5 / 27$ & $5 / 29$ & $6 / 6$ & & Yes & $\ldots$ & Ten. & 4 & \pm \\
\hline 17 & 3 & $5 / 26$ & $5 / 29$ & $5 / 30$ & $\ldots$ & Yes & .... & $2 \mathrm{Fam}$. & 6 & 6 \\
\hline 18 & 6 & $4 / 6$ & $4 / 10$ & $4 / 19$ & $\ldots$ & Yes & $\ldots$ & P. H. & 6 & 10 \\
\hline 19 & 13 & $4 / 21$ & $4 / 28$ & 5/ 6 & $\ldots$ & Yes & .... & P. H. & 6 & 8 \\
\hline 0 & 4 & $5 / 5$ & $5 / 13$ & $5 / 13$ & $\ldots$ & Yes & $\cdots$ & Ten. & 8 & j \\
\hline 21 & 6 & $3 / 12$ & $3 / 16$ & $3 / 18$ & $\ldots$ & Yes & $\ldots$ & $2 \mathrm{Fam}$. & 6 & 7 \\
\hline 22 & 4 & $4 / 29$ & $5 / 4$ & $\bar{\delta}_{t}^{\prime} 15$ & .... & Yes & .... & T'en. & 4 & 4 \\
\hline 23 & $21 / 2$ & $4 / 14$ & $4 / 20$ & $4 / 27$ & $\ldots$ & Yes & .... & 'Ten. & 5 & 4 \\
\hline 24 & 8 & $4 / 14$ & $4 / 20$ & $4: 20$ & $\ldots$ & Yes & & Ten. & 5 & \pm \\
\hline 25 & 9 & $4 / 20$ & $4 / 22$ & $5 / 14$ & $\ldots$ & 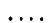 & Yes & & 6 & 4 \\
\hline 26 & $3 \frac{1}{2}$ & $4 / 20$ & $4 / 22$ & $5 / 13$ & ... & $\cdots$ & Yes & $2 \mathrm{~F}$ & 6 & 4 \\
\hline 27 & 3 & 4/ 1 & 4) 4 & $4 / 14$ & $\ldots$ & Yes & .... & & 6 & 4 \\
\hline 28 & 2 & $4 / 1$ & 4 & $4 / 14$ & $\ldots$ & Yes & .... & $2 \mathrm{Fa}$ & 6 & 4 \\
\hline 29 & 10 & 6/ 3 & $6 / 5$ & $6 / 13$ & $6 / 5$ & .... & $\ldots$ & & 5 & 5 \\
\hline 30 & 6 & $6 / 13$ & $6 / 15$ & $6 / 28$ & $6 / 15$ & . & & & 5 & 5 \\
\hline & 3 & & $5 / 26$ & $6 / 7$ & .... & Yes & $\ldots$ & $\mathrm{Te}$ & 5 & 4 \\
\hline 3 & 2 & 4/ 8 & $4 / 11$ & $4 / 17$ & $\ldots$ & Yes & & P. H. & 7 & 10 \\
\hline 33 & 5 & 4) 8 & $4 / 11$ & $4 / 8$ & .... & Yes & & P. H. & 7 & 10 \\
\hline 34 & 10 & $3 / 15$ & $3 / 18$ & $4 / 16$ & $\ldots$ & .... & Yes & Ten. & 9 & 6 \\
\hline 35 & 12 & $3 / 15$ & $3 / 18$ & & $\ldots$ & $\because \cdots$ & Yes & 'Ten. & 9 & 6 \\
\hline 36 & 8 & & & $5 / 1$ & $\ldots$ & Yes & $\ldots$ & & 4 & 5 \\
\hline 37 & 1 & $5 / 7$ & 5/ 8 & $5 / 17$ & $\ldots$ & Yes & $\ldots$ & & 4 & 5 \\
\hline 38 & 3 & $4 / 15$ & $4 /$ & & $\ldots$ & Yes & $\ldots$ & & 5 & 4 \\
\hline & 5 & & 4) & & & Yes & $\ldots$ & & 6 & 7 \\
\hline 40 & 2 & $3 /$ & $4 / 11$ & $4 / 20$ & $\ldots$. & Yes & . & & 6 & 7 \\
\hline 41 & 9 & $3 / 1$ & & & $\ldots$ & & Yes & & 13 & 5 \\
\hline 42 & $31 / 2$ & & & $3 / 3$ & $\ldots$ & Yes & .... & & 6 & 6 \\
\hline 43 & $1 \frac{1}{2}$ & & & & .... & Yes & .... & & 6 & 6 \\
\hline 44 & 9 & & 31 & & $\ldots$ & Yes & $\ldots$ & Te & 6 & 6 \\
\hline 45 & 5 & 4/ 9 & $4 / 14$ & $4 / 1$ & $\ldots$ & Yes & $\ldots$ & & 5 & 4 \\
\hline 46 & $\theta^{*}$ & 4) 9 & & & . & Yes & .... & & 5 & 4 \\
\hline 47 & $1^{1 / 2}$ & & & & $6 / 9$ & & $\cdots$ & Ten. & 4 & 4 \\
\hline 48 & 6 & $3 / 28$ & $3 / 31$ & 4) & 4) 2 & $\ldots$ & & & 5 & 2 \\
\hline 49 & 10 & & & & & & Yes & T'en. & 3 & 6 \\
\hline 50 & 5 & & 5/ 7 & & & Yes & & Ten. & 7 & 4 \\
\hline 51 & 17 & $4 / 23$ & $4 / 27$ & $5 / 13$ & $\ldots$ & & Yes & 'Ten. & 5 & \\
\hline 52 & 2 & & & 51 & & Yes & & & 8 & 6 \\
\hline 53 & 8 & $3 \longdiv { 2 4 }$ & $3 / 2$ & 4) & $\cdots$ & Yes & $\ldots$ & & 6 & 2 \\
\hline 54 & 6 & $3 / 2$ & 31 & 4/ 1 & & Yes & $\ldots$ & Ten. & 6 & $\underline{2}$ \\
\hline 55 & 16 & & $5 /$ & $5 / 5$ & $5 / 5$ & & $\ldots$ & ren. & 6 & 5 \\
\hline 56 & 16 & $4 / 15$ & $4 / 22$ & $4 / 22$ & & Yes & $\ldots$ & 2 Fam. & 5 & 6 \\
\hline 57 & 7 & $6 / 16$ & 6 & $6 / 2$ & $6 / 23$ & & & Ten & 5 & 3 \\
\hline & 9 & $5 / 28$ & & 61 & $6 / 5$ & $\ldots$ & .... & & 6 & 6 \\
\hline 5 & 7 & $6 / 2$ & & 6) 5 & 6) 7 & $\ldots$ & $\ldots$. & 2 Fam. & 6 & 6 \\
\hline 60 & 4 & & & $6 / 12$ & $6 / 27$ & $\ldots$. & & 2 Fam. & 6 & 6 \\
\hline 61 & 3 & 5) 4 & & $5 / 10$ & $\ldots$ & $\ldots$ & Yes & Ten. & 4 & 4 \\
\hline 68 & 2 & 5) 2 & & $5 / 13$ & $\ldots$ & $\ldots$ & Yes & 'Ten. & 5 & 6 \\
\hline 6 & 8 & 4/ 8 & $4 / 10$ & $?$ & $\ldots$ & Yes & . & $\mathrm{Te}$ & 7 & 4 \\
\hline 64 & $10^{*}$ & 4) 8 & $4 /$ & $?$ & $\cdots$ & Yes & $\ldots$ & Ten. & 7 & 4 \\
\hline 65 & 6 & & $4 / 10$ & $?$ & & Yes & $\ldots$ & T'en. & 7 & \\
\hline 66 & $11^{*}$ & 6) 8 & $6 / 11$ & $6 / 13$ & $6 / 17$ & Yes & $\cdots$ & 2 Fam. & 6 & 7 \\
\hline 67 & 6 & 4) 7 & $5 / 11$ & $6 / 3$ & 6) 3 & & & 'Ten. & 5 & 4 \\
\hline 68 & 3 & $3 / 25$ & $3 / 30$ & 4/11 & & & Yes & 'Ten. & 6 & \\
\hline 69 & 6 & $11 / 1$ & $11 / 4$ & $11 / 21$ & .. & Yes & & Ten. & 4 & 4 \\
\hline 70 & 7 & $11 / 12$ & $11 / 14$ & $11_{f}^{\prime} 19$ & $\ldots$ & & Yes & Ten. & 6 & \\
\hline
\end{tabular}

* Months. 
mit without change of domicile, provided they are not susceptible or that the incubation period of five days has expired.

During the period during which this study was made, the duration of quarantine for scarlet fever was thirty-five days from the onset of the disease, provided there were no purulent discharges, and desquamation had ceased. At present this period has been decreased to thirty days, in accordance with the rules of the New York State Department of Health. There is no placarding of private houses or of twofamily houses where there is separate entrance or exit to apartment. Tenement houses are placarded on the door opening into the public hall. In Table 3 is shown the number of adults in the family without reference to their stisceptibility, as these data have not been required on history cards, and for this reason cannot be given.

In the seventy later cases there are twenty-five that appeared within five days from the date of placarding as follows:

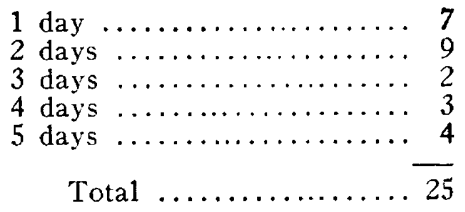

The incubation period of scarlet fever being taken as from one to five days, responsibility for the occurrence of the later cases cannot be charged against any method of quarantine. There are also other cases which should not be charged to faulty quarantine, as in Cases $11,12,13,63,64$ and 65 , and in which diagnosis was made by observing the presence of desquamation. In these cases the later cases, taking the date of their report as a guide in terming them such, are really the primary cases, and the case first reported the later one.

Cases 6 and 7 are also of interest and should be eliminated. In these cases the original case was diagnosed as diphtheria by the attending physician, cultures negative, onset June 22, placarded June 26, and terminated on negative cultures without fumigation July 23. Cases 6 and 7 were reported August 18 and placarded the same date.

Cases 36 and 37 are not chargeable to faulty quarantine methods. Primary case was diagnosed and reported as measles by attending physician, May 7 , and placarded as such. The case was terminated in five days, and Cases 36 and 37 were not reported until May 21, with an onset May 17 . Case 67 shows onset of primary case April 7, terminated and fumigation performed May 11, and onset of later case was Iune 3.

In Case 5, the primary case was removed to the hospital, and fumigation was done August 25. Onset of later case was Angust 31. In Case 29, the primary case was removed to the hospital June 5 , and fumigation was performed June 6 . The onset of the later case occurred June 13 . In Case 30, the primary case was removed to the hospital and fumigation was performed June 15 . Onset of the later case occurred Iune 28 . In a study to determine the value of quarantine in preventing the occurrence of later cases, it is fair to eliminate these thirty-nine cases.

Of the remaining thirty-one cases, certain cases are of considerable interest. In Case 1, the residence of the susceptible child was changed at the time of pla- carding the primary case June 22. The onset of the later case was July 9, seventeen days subsequent to change of address. This would indicate a long period of incubation or that infection had been carrier. Cases $2,3,25,26,34$ and 35 were supervision cases. Violation of quarantine had been observed; a.patrolman of the health squad was sent to warn, but before the cases could be forced to the hospital according to the present procedure, the later cases dereloped. Two cases occurred in children under the age of 1 year. One case (Case 51) occurred over the age of 16 years.

Thirty-one later cases occurring in 1,610 reported cases gives a percentage of 1.925 against 1.087 in Grade $A$ quarantine in Chicago.

The proportion of later cases to susceptibles, adults and children in Grade $\mathrm{A}$ of the Chicago study is 0.8929 per cent. The proportion in the Brooklyn study, 2,171 susceptible children and thirty-one later cases, is 1.4279 per cent. This should not be considered proof of the efficacy of the Grade A quarantine of Chicago, however, as our study does not include adults, of whom there were 3,207 , because we have no data to show the exact number who were susceptible. Furthermore, the percentage shown in the Brooklyn cases includes observation and supervision cases as contrasted with Grade A alone.

Finally, attention is called to the statement in the article by Dr. Young: "By 'secondary case' is meant one occurring among the susceptibles in the family at a date at least two weeks beyond the usually recognized limits of the period of incubation." It is extremely difficult to understand why this arbitrary limit of "two weeks beyond the usually recognized limits of the period of incubation" has been established by $\mathrm{Dr}$. Young in the determination of later cases. This woutd be a period of nineteen days, and out of the seventy cases studied in Brooklyn, there were only ten occurring after this period. It seems evident that this is an error and that the method of quarantine may be questioned in any case occurring after the period of incubation has expired from the date that the case was quarantined and placarded, with certain exceptions as in cases noted above.

During the years from 1907 to 1914 , the quarantine period for scarlet fever in Brooklyn was thirty-five days. No children in the infected family were permitted to attend school though residence was changed. On first evidence that isolation was not proper, without warning, the case was forced to the hospital. In view of the large increase in population and the fact that in 1914 the present liberal quarantine was in effect, the following statistics are of interest if the number of cases reported is in direct relation to the grade or excellence of quarantine:

$\begin{array}{lrrrrr}\text { Year Cases } & \text { Year Cases } & \text { Year } & \text { Cases } & \text { Year Cases } \\ 1907 \ldots . .5,471 & 1908 \ldots . .8,236 & 1909 \ldots \ldots 4,490 & 1910 \ldots .6,810\end{array}$ $\begin{array}{llll}1907 \ldots . .5,471 & 1908 \ldots . .8,236 & 1909 \ldots .4,490 & 1910 \ldots 6,810 \\ 1911 \ldots .449 & 1912 \ldots .64,649 & 1913 \ldots .4,614 & 1914 \ldots .716\end{array}$

The question presents itself: Is the present system of quarantine in New York City satisfactory? Two criticisms may be offered in reply to this question:

A. In six cases out of thirty-one, violations were noted and later cases developed before forcible removal could obtain. This would seem to indicate some modifications of the present procedure of forcible removal similar to Grade $\mathrm{C}$ of Chicago.

B. Out of 1,610 cases, 1,300 of which were quarantined at home and 761 of these in tenements with 
2,575 susceptible children, only 157 were supervision cases.

The difficulty here is not in the spirit but in the number of field workers. Studies are made in a congested district, by a clever, bright, capable nurse. skilled in every way for the work in hand. On the basis of the number of calls which can be made by this trained observer, the number of field workers is determined, and it is evident that the same work cannot be accomplished by nurses of average ability in districts which are less congested.

The present system certainly interferes less with the school attcndance of children and offers less hardship to the family. The study of 1,610 cases may not be sufficient to arrive at definite conclusions but it offers sufficient evidence to cast doubt on the conclusions that the system of classified quarantine in Chicago has justified itself. The weight of evidence would tend to show that the liberal quarantine of the health department of New York is the more justifiable, but this judgment should be supported by the sturdy of a larger number of cases.

\section{THE DIACNOSIS AND TREATMENT OF GONOCOCCAL VULVOVAGINITIS IN INFANTS AND YOUNG CHILDREN}

\section{CHARLES C. NORRIS, M.D.} PIHILADLPHIA

The frequency with which gonococcal vulvovaginitis is seen in the young, the difficulty often experienced in demonstrating the specific micro-organism, and the extreme chronicity of this form of neisserian infection are known to most workers in this field of medicine. Vulvovaginitis may be due to various organisms, but, unfortunately, in the large majority of cases occurring among children, the gonococcus is the exciting factor. The combined statistics of Hurdon, ${ }^{1}$ Koplik, ${ }^{2}$ Romniceanu and Robin, ${ }^{3}$ Dukelski ${ }^{4}$ and Plomley ${ }^{5}$ show that, in a large series of cases, 80.29 per cent. were due to the gonococcus of Neisser. For this reason, and because of the difficulty with which, as a rule, the organism can be demonstrated, all suspicious cases of inflammation in the vulvovaginal region should be treated as if they were of specific origin, until they are proved to be nonspecific. This is especially important in institutional work, in which the danger of transmitting the infection to other children is great.

During the acute stage of the attack, the gonococcus is usually readily isolated; later, however, when the disease has becone chronic and the discharge is scanty, the organism can be demonstrated only with great difficulty. Not only is the demonstration of the gonococcus of importance in making the diagnosis, and, as a result of this, instituting appropriate treatment and safeguarding others against infection, but also it is of cqual importance to determine from its absence, after a course of treatment, when a cure has been effected. In recent years the complement fixation and the cutaneous tests have proved of great value in the diagnosis

1. Hurdon, E., in Kelly and Noble: Gynecology and Abdomina Surgery, Philadelphia and London, 1907, ii.

2. Koplik: Jour. Cutan. and Gren.-Urin. Dis., 1893, ii.

4. Dukelski: Jahrb. f. Kinderh., 1904, lix, 397. of gonorrhea. Unfortunately, however, in the case of vulvovaginitis, the negative results obtained by these tests cannot be accepted as giving a free bill of health to the child. On the other hand, positive results are to be regarded as diagnostic in practically all cases in which the tests have been carried out by an experienced bacteriologist. It follows, therefore, that these tests are of secondary importance in determining when a cure has been effected - a point of great practical importance. In order to decide this question, we are, therefore, still compelled to rely, at least to a large extent, on the bacteriologic examination.

I have previously mentioned the difficulty with which the organism is demonstrated in chronic cases. This difficulty. is increased in those cases which have received proper treatment, for the physical signs are of ten practically absent, and there may be little or no appreciable discharge. If, under such circumstances, the organisms are present in spite of the fact that they cannot be detected microscopically, treatment is likely to be discontinued, and, as a result, the disease assumes rencwed activity, and the infection is greatly prolonged. It is of the utmost importance, therefore, for the clinician to be able to determine when the organisms are absent, and when they are present.

In 1910, Van Gieson ${ }^{6}$ suggested a method of determining the presence of the gonococcts by examining the centrifuged washings of the vagina. I have employed this method for years in all doubtful cases, and have fosund that, by its use, the gonococcus can more readily be demonstrated. The following technic is employed: The child is placed in the Sims left lateral position, or, in the case of an infant, is held in the nurse's lap, with the buttocks elevated. The external genitalia are exposed and wiped with a cotton sponge wet with mercuric chlorid solution. The labia are next separated, and if any discharge is present, this is removed by means of a dull knife-blade or any similar instrument. The cotton swab usually employed for this purpose is of lessened value, since it tends to retain within the meshes of the cotton the cellular elements of the discharge, the most valuable elements, the demonstration of the organism intracellularly being of prime importance. Furthermore, the act of rubbing the swab over a glass slide has a tendency to destroy the pus-cells, so that when the smear is examined, more extracellular organisms will be found to be present. The smear obtained may be examined at once, and if found negative for gonococci, or if only an insufficient amount of discharge for examination can be secured, the following procedure is employed:

The patient is placed in an elevated position, so that the solution will not run out of the vagina, and with a soft, all-rubber eye syringe, about one-half ounce of $1: 5,000$ mercuric chlorid in normal salt solution is injected. ${ }^{7}$ If the patient is in the proper position, and the bladder and rectum are moderately empty at the time of examination, the vagina will be ballooned out by the atmospheric air. This is an important detail. With the vagina thus partially filled with solution and thoroughly distended, a smooth glass rod is introduced and the various parts of the vagina are rubbed with it. This procedure is done for the purpose of detaching any adherent secretion. In cases in which

6. Van Gieson: Med. Rec., New York, June, 1910.

7. The making up of the mercuric chlorid in salt solution was sug. gesied to n:e by Dr. John A. Kolmer. The organisms stain better and the pus and epithelial cells are fixed more readily with the salt
solution than when a watery mercuric chlorid solution is employed. 